\title{
System for the Management of the Continuity of Use of Medical Devices in Hospitals
}

\author{
Manuela Stroili, Elena Pavan, Marino Gorela and Fulvio Kenda \\ Public Hospital of Triest, Hospital Maggiore, Piazza Ospedale Maggiore, and University of Triest, CAP 34100 Trieste, Italy
}

\begin{abstract}
The Technical Services and the Medical Administration of the Hospitals of Trieste have been working for years to ensure the optimal functioning of the Surgery, Intensive Care, Diagnostics and Research Services offered to the Patients and to the University in an 800-bed hospital complex, transforming and innovating the buildings and support installations. We have dedicated special attention to the technologies necessary to guarantee the continuity of the power supply to the electromedical devices, increasingly numerous in highly specialized hospitals. We report the power of the generator sets and the UPS and our opinion that their power must be related to the overall consumption of the hospital, with a reserve margin.
\end{abstract}

Key words: Generator set, UPS, hospital planning, design and development electrical system, Master University, HTA, health technology management and assessment, safety, hospital medical devices.

\section{Introduction}

This paper aims to reflect on the current standards for the planning and building of electrical installations in large and big hospitals that are engaged in surgery and emergency/urgency procedures.

The large dimensions of a hospital generally indicate the presence of specialized beds for medical, surgical and for general, pediatric and cardiologic intensive care in a proportion of $3-5 \%$ of the total, a value that includes a separate area for infected patients, equipped with a washbasin controlled by a pedal behind every bed.

All of these health activities use a large number of MD (medical devices), which must be constantly efficient to guarantee their life-saving functions and the continuity of surgical and outpatient procedures for patients. The MD are powered by electric energy and this must be guaranteed without interruption. Since the 1990s, we have witnessed developments in the project management and building of electrical installations in hospitals with an increase in the endowment of electric

Corresponding author: Manuela Stroili, medical doctor, professor in health planning in SMMCE master, research fields: FMEA risk analysis, hospital design and development, health assessment for medical devices and rehabilitative, therapeutic and diagnostic pathway.E-mail: manuela.stroili@tin.it. generator sets and UPS to guarantee an uninterruptible power supply for an increasing number of health services. At the same time, Italian legislation has reduced the number of hospital beds funded by the public health service from 6.5 beds in 1985 to 3 beds in 2015 for every 1,000 inhabitants, concentrating the hospital medical devices even more, numerically and in terms of technical complexity.

\section{The Trieste Experience}

2.1 The Hospital of Cattinara with the Emergency-Urgency Department and the University Hospital of Trieste

The University Hospital of Trieste comprises the Hospital of Cattinara and the Ospedale Maggiore built in 1841 and undergoing renovation, not describe it here. The Cattinara Hospital complex at Trieste in the Friuli-Venezia Giulia Region has been active since 1984 and consists of two 15-floor towers with 840 beds, two outpatient departments and another 4-floor building, the Cardiology Center, active since 2004, with the functions shown in Table 1.

In the hospital area, there are also buildings with technological installations, outpatient departments and 
Table 1 The Hospital of Cattinara.

\begin{tabular}{|c|c|c|}
\hline Buildings & Services & Beds \\
\hline $\begin{array}{l}\text { Single block comprising } 2 \\
\text { towers and health services }\end{array}$ & $\begin{array}{l}\text { Emergency room and temporary observation } \\
\text { Operating rooms } \\
\text { Hepatology } \\
\text { Gastroenterology } \\
\text { Laboratories } \\
\text { Nuclear Medicine } \\
\text { Radiological TCM 256, MR, and ultrasound } \\
\text { Transfusion, } \\
\text { Research laboratories }\end{array}$ & \begin{tabular}{|l} 
Resuscitation \\
Stroke unit \\
Hemodialysis \\
Medicine \\
Surgery \\
Laparoscopy neurosurgery \\
Vascular surgery \\
Reconstructive plastic surgery \\
Orthopedics \\
Urology \\
Otolaryngology (head and neck surgery)
\end{tabular} \\
\hline $\begin{array}{l}\text { Cardiology Center and } \\
\text { Pathological } \\
\text { Anatomy Service }\end{array}$ & \begin{tabular}{|l|} 
Operating rooms \\
Hemodynamics rooms \\
Helipad laboratories \\
Technology Assessment Office
\end{tabular} & $\begin{array}{l}\text { Coronary Care Unit } \\
\text { Cardiology } \\
\text { Heart surgery }\end{array}$ \\
\hline
\end{tabular}

offices, as well as classrooms for teaching and training the personnel and for scientific conferences. The hospital contains the only Emergency-Urgency Department in Trieste and is continuously active throughout the year for a resident population of 235,700 inhabitants; it also treats patients from neighboring cities and 1,400 people per year from other regions. The social report for the hospital for the last year lists 27,488 patients hospitalized, 12,926 surgical operations, 1,536 cardiac catheterizations, 534 coronary angioplasties, 366 coronary artery bypass procedures, 114,284 radiological examinations, 1,818,427 laboratory tests and overall annual funding for the current year of 268 million Euros.

\section{The Cattinara Hospital Building Complex and Electrical Installations}

We will now describe the building and the electrical installations in general and dedicated to health technologies.

\subsection{Cattinara Hospital Building}

The overall area of Cattinara Hospital and Cardiology Center described above occupies an area of 113,600 square meters, whereas the covered area is 23,300 square meters, in addition to car parks and a green area. The volume of the buildings is 438,000 cubic meters for all the health care and research activities, excluding the classrooms.
The kitchen for patients and employees is outside and the heating of the food and washing dishes are just made in hospital. The complex has 925 open-air car parking spaces for the personnel, students, family members, patients and disabled people and an area equipped and illuminated for nighttime helicopter landing in ephemeris time. It has easy connections to the town center, with 8 bus lines and 24-hour taxi service. A crèche for the children of the hospital personnel is under construction.

\subsection{General Electrical Installations of the Hospital}

The electrical system of Cattinara Hospital Complex comprises a main electricity substation that receives energy from an external energy supply company at $27.5 \mathrm{kV}$ transforming it to 6,000 Volts. The hospital is supplied with electric energy via a 6 $\mathrm{kV}$ ring with 5 electrical transformer and distribution rooms situated in each main building.

The hospital complex has a daily electricity consumption of 50,000 $\mathrm{kWh}$ to supply all the services and the medical devices for diagnostic and therapeutic systems, excluding the heating systems and 30\% of the cooling systems that are powered by gas.

\subsection{Power of the Electric Generator Sets Installed}

Electric generator sets, diesel generator, or generator unit, are supplementary and substitute systems that guarantee the power supply in the absence of normal 
external electrical supply and are activated within 15 seconds after a power failure, preventing a blackout in the hospital. They are supplied by diesel oil contained in tanks of suitable dimensions to guarantee the full functioning of the generators for at least 24 hours and have an average capacity that varies between 3,000 and 5,000 liters. They are continuously filled from a fuel tanker. In 1984, 2 electric generators, each with a power of $500 \mathrm{kVA}$, guaranteed the continuity of the electrical supply to the original Hospital of Cattinara. In May 2008, both were replaced by new systems having an overall power of 3,200 kVA and 5 more generators were added; Table 2 describes the services to which they are dedicated. Overall, the power supply installed is 4,600 kVA.

In case of further problems, a priority plan has been drawn up by the hospital medical administration together with the technical services, establishing that the less critical health services should be gradually detached from the electricity supply.

\subsection{Power of the UPS Installed}

Our Uninterruptible Power Supply units or UPS, are devices able to supply stabilized and continuous electrical power to the installations connected to them, as listed in Table 3. This power is supplied for a limited period, for at least an hour at full power, but without interruption and allowing the generators to be activated within 15 seconds. The uninterruptible power supplied by the UPS guarantees the energy supply to the electromedical device connected to it, which does not cease its activity, such as a diagnostic or therapeutic coronary angioplasty in the case of acute myocardial infarction. These particularly delicate and complex techniques come under the responsibility of the Emergency Department.

\section{Principles of Electrical Continuity and of Generator Sets and UPS Working}

Italian health legislation has established the general principle that in hospitals an electric continuity must be

Table 2 Electric generator sets of Cattinara Hospital-Trieste.

\begin{tabular}{llll}
\hline Hospital area & n. generator sets & Power & n. starter batteries \\
\hline Block 1 & 1 & $1,600 \mathrm{kVA}$ & 4 \\
Block 2 & 1 & $1,600 \mathrm{kVA}$ & 4 \\
Cardiology center & 1 & $500 \mathrm{kVA}$ & 2 \\
Reserve & 1 & $250 \mathrm{kVA}$ & 2 \\
Helipad & 1 & $150 \mathrm{kVA}$ & 1 \\
Classrooms & 1 & $250 \mathrm{kVA}$ & 2 \\
Pathological & 1 & $250 \mathrm{kVA}$ & 2 \\
Anatomy service & 7 & $4,600 \mathrm{kVA}$ & 17 \\
Total & & & \\
\hline
\end{tabular}

Table 3 UPS of Cattinara Hospital-Trieste.

\begin{tabular}{llll}
\hline Hospital area & N. UPS & Total power & N. battery elements \\
\hline Main center & 3 & $600 \mathrm{kVA}$ & 560 \\
Rescue center & 1 & $45 \mathrm{kVA}$ & 18 \\
Emergency center & 1 & $200 \mathrm{kVA}$ & 80 \\
Outpatient department & 3 & $90 \mathrm{kVA}$ & 85 \\
Cardiology center & 3 & $150 \mathrm{kVA}$ & 165 \\
Hemodynamics & 1 & $250 \mathrm{kVA}$ & 60 \\
Classrooms & 1 & $30 \mathrm{kVA}$ & 32 \\
Anatomic pathology & 2 & $60 \mathrm{kVA}$ & 64 \\
Installations rooms & 2 & $165 \mathrm{kVA}$ & 98 \\
Total & 17 & $1,600 \mathrm{kVA}$ & 1,162 \\
\hline
\end{tabular}


maintained to guarantee assistance and care for hospitalized patients, without harm or serious lesions caused by the interruption of the medical or surgical activity underway [1, 2]. The technical legislation has established, in various editions of Standard CEI 64-8, rules regarding the building and use of electrical installations for medical use also with reference to electric continuity [3-6, 8]. With this work we ask again the Scientific Community to identify a quantitative standard and promote the production of a Technical Legislation defining the power and the number of generator sets and UPS to install in hospital in relation to the quantity of electricity consumption expected or detected.

\subsection{Electric Generator Sets and UPS}

A generator set is a machine composed of a thermic engine coupled to an electrical generator apt to transform heat combustion energy into electrical energy. It is connected to the hospital's electricity substation and by means of a line switch to the appliances, which are supplied with emergency electricity. When the electronic sensors coupled to the generator sense that the voltage has dropped sharply, or is totally absent, the generator unit is activated within 15 seconds and powers appliances and electromedical devices connected to it, replacing the ordinary voltage, allowing resumption of the activity. The engine therefore starts to operate, via circuit breakers, if the energy supply company fails to deliver electricity to the hospital.

The current interpretation of the above standards, with which we agree, establishes that the electric generator sets should be dimensioned with an overall power able to fully support the electricity load required by the entire hospital complex, to perform its full health activity. In line with this reasoning, it is also appropriate to program and install in the hospital a power reserve for the generators in order to guarantee the performance of planned maintenance activities and to deal with sudden failures of dedicated generators; in this regard, see the list of generators in Table 4. The interruption of power, even for only 15 seconds, before activation of the Generators, can nonetheless determine a loss of information, video and computer images, because of the need to restart equipment, bleeding of a wound because the electric bistoury has switched off, and other more or less serious inconveniences to the patients, but also to the health care professionals. The UPS has been introduced to remedy this problem [10].

\subsection{UPS-Uninterruptible Power Supply}

An uninterruptible power supply or UPS is a device used in a grid, always with a power supply, to maintain medical and electric appliances in general constantly powered with alternating current electricity. They consist essentially of a primary converter that transforms alternating current into direct current to power a series of continually operating batteries, where electricity is accumulated, and from a second converter that transforms direct current into alternating current to power the appliance connected, such as electric scalpels, operating lights, lung ventilators and other electric medical devices.

\section{The Electricity Consumption of an 800-Bed Hospital with Medical Devices}

\subsection{Annual Electricity Consumption of the Hospital Complex of Cattinara}

Table 4 shows the total electricity consumption and the average for the last 5 years of activity at full capacity of the whole Hospital Complex of Cattinara in Trieste, including the helipad, lighting of the car park,

Table 4 Yearly electricity consumption and yearly average.

\begin{tabular}{lc}
\hline \multicolumn{2}{l}{ Electricity consumption of the Cattinara Hospital Complex } \\
\hline Year 2010 & $17,499,600 \mathrm{kWh}$ \\
Year 2011 & $18,126,325 \mathrm{kWh}$ \\
Year 2012 & $19,061,761 \mathrm{kWh}$ \\
Year 2013 & $18,263,737 \mathrm{kWh}$ \\
Year 2014 & $18,359,886 \mathrm{kWh}$ \\
Last 5 years & Yearly average 18,262,261 kWh \\
\hline
\end{tabular}


entrances and classrooms. A degree of stability in consumption can be observed, with a peak in 2012, owing to the increased summer air conditioning necessary to maintain a suitable microclimate for patient hospitalization and care, due to the strong increase in atmospheric temperature that year.

Consumption has increased because of the need for heating due to the age of the external door and window frames, which have high levels of heat conduction.

\subsection{Comparison of Electricity Consumption at} National and International Levels

Our electricity consumption is in line with the consumption of similar hospitals in the Friuli Venezia Giulia Region, as shown in Fig. 3 and Table 5 [9].

Fig. 3 shows that hospitals under the regional healthcare system in the region have a much lower electricity consumption per square meter than US and British hospitals. The electricity consumption is in line with European hospitals in Germany and Belgium possibly as a result of the lower percentage of highly specialized diagnostic and treatment equipment and since they use equipment for MRI scan, PET-CT, narrow band imaging and video endoscopy systems, surgical lasers, robot technology, etc. mainly during the day. Another reason might be the diversification in energy sources.

Additionally, meals are prepared outside the hospital.

It must be noted that the overall demand for electricity in the Hospital of Cattinara is met, as shown in Figs. 1 and 2, also with the gas supply for heating (heating consumption) for twice as much as for electricity demand, with an increase in the trend after 2006, also as a result of the implementation of the new co-generation plant.

\subsection{Electric Generator Sets Consumption}

We have shown in Fig. 1 the quantity of electricity produced and the hours when the generator sets were switched on, necessary both to make up for the sudden absence of electricity, guaranteeing the continuation of the healthcare activities, and to perform the monthly performance tests of generators.

\section{Electricity Consumption for the Use of the Therapeutic and Diagnostic Systems}

As described at the beginning of this paper, the Hospital Complex of Cattinara must guarantee the daily operation of its healthcare equipment for 365 days a year and at all hours of the day and night, without interruption, because it is within the emergency hospitals network and it must always admits and treats, also surgically, every patient who comes to the Emergency Department and who is in need of care.

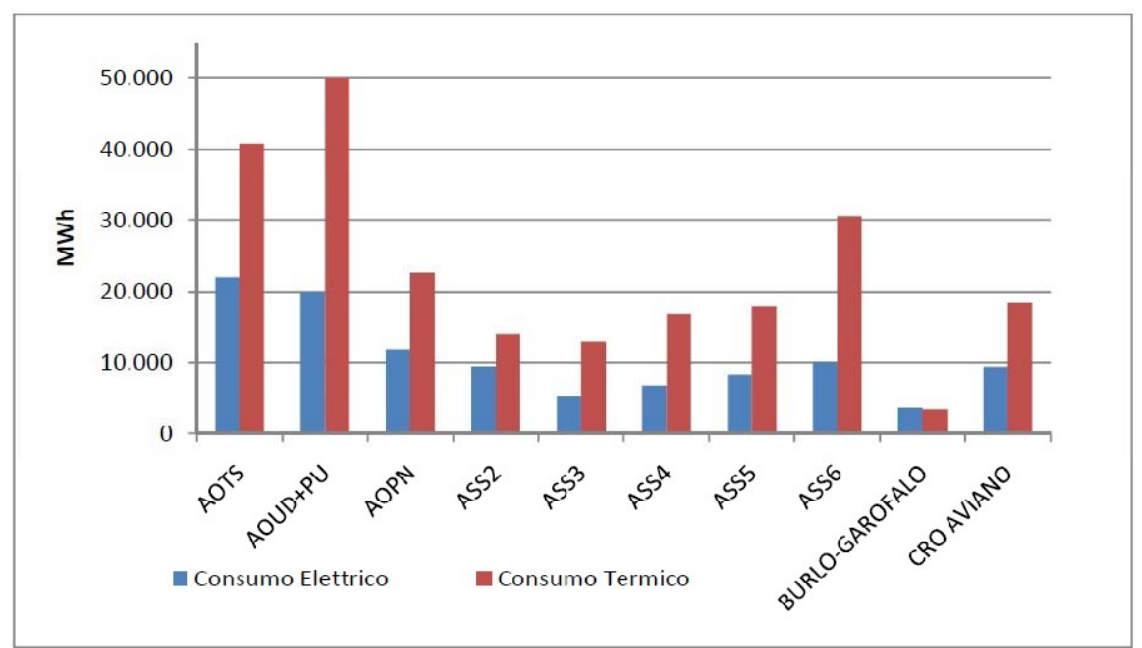

Fig. 1 Thermic consumption (higher red bars) and electricity consumption (lower blue bars) of hospitals in the Friuli Venezia Giulia Region in 2006 (see reference No. 9). 


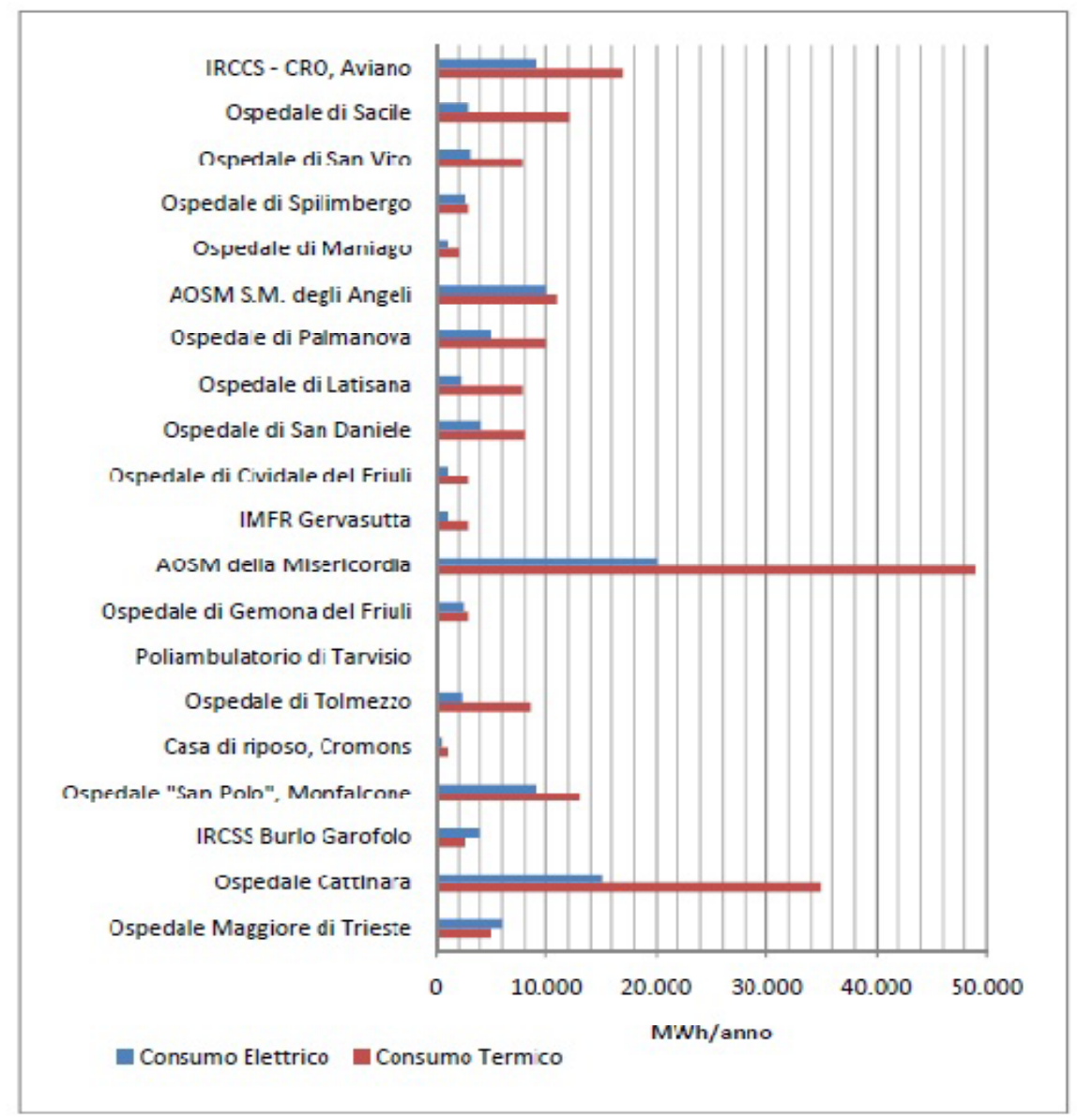

Fig. 2 Thermic consumption (higher red bars) and electricity consumption (lower blue bars) of hospitals in the Friuli Venezia Giulia Region in 2006 (see reference No. 9).

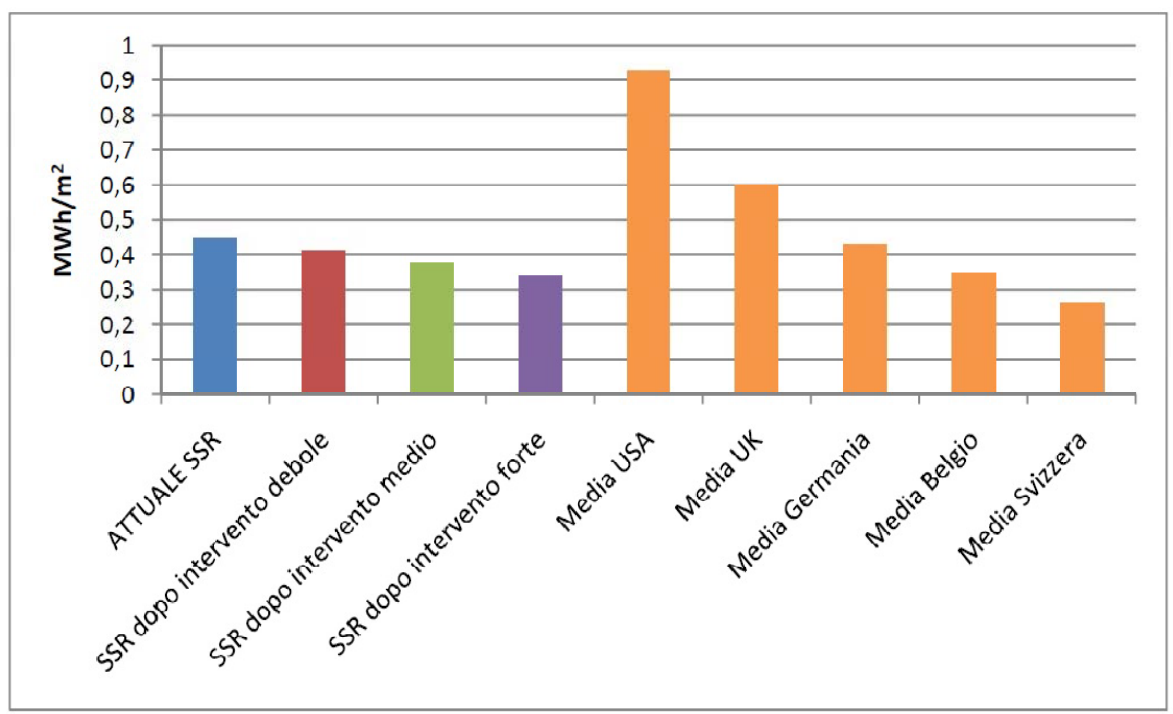

Fig. 3 Current specific electricity consumption indexes in public hospitals in the Friuli Venezia Giulia Region (currently under the regional healthcare system, year 2006) vs. hospitals in other countries. 
Table 5 Electrical generator sets activity.

\begin{tabular}{llll}
\hline Generator sets & Power & Hours switched on & $\begin{array}{l}\text { Electricity produced } \\
\text { from 6/2008 to 2/2015 }\end{array}$ \\
\hline Block 1 & $1,600 \mathrm{kVA}$ & 26 & $4,500 \mathrm{kWh}$ \\
Block 2 & $1,600 \mathrm{kVA}$ & 26 & $2,118 \mathrm{kWh}$ \\
Cardiology center & $500 \mathrm{kVA}$ & 26 & $1,500 \mathrm{kWh}$ \\
Reserve & $250 \mathrm{kVA}$ & 0 & 0 \\
Helipad & $150 \mathrm{kVA}$ & 26 & $400 \mathrm{kWh}$ \\
Classrooms & $250 \mathrm{kVA}$ & 26 & $600 \mathrm{kWh}$ \\
Anatomic pathology & $250 \mathrm{kVA}$ & 26 & $600 \mathrm{kWh}$ \\
Total & $4,600 \mathrm{kVA}$ & 26 & $9,718 \mathrm{kWh}$ \\
\hline
\end{tabular}

6.1 The First Generator Sets for Electrical Continuity

The original plan, when the Hospital of Cattinara opened in March 1984, envisaged the installation of 2 generators of $500 \mathrm{kVA}$ each, for a total 1,000 kVA.

This power was insufficient to supply all the medical devices and electrical health appliances, therefore the hospital's health administration, together with the doctors and surgeons, established which medical devices were to be connected to the 2 generators.

The electrical appliances with electrical continuity chosen were the lighting for the escape routes, night safety lights in the in-patient wards, stretcher lifts and several public elevators, the operating rooms, the electromedical devices in the resuscitation and emergency hemodialysis unit. The operating rooms and intensive care with emergency hemodialysis were connected to the technological generation of the UPS of the time, named dynamic continuous power supply.

Then in the year 2008, the two $500 \mathrm{kVA}$ generators sets were replaced by two $1,600 \mathrm{kVA}$ generators dedicated only to the two towers with beds and health services and able to substitute each other in the case of failure of one of the two generators. It was thus possible for the hospital to increase the number of electromedical devices serviced [10].

\subsection{Annexation of the Cardiology and Heart Surgery Center}

In the year 2004, the Cardiology Center annexed to the Hospital of Cattinara was opened and another two $500 \mathrm{kVA}$ generators sets were installed to guarantee the continuous operation of the new dedicated electromedical devices and of the civil installations contained within it.

Therefore, in a 30-year span the healthcare technology system content inside the hospital has increased, although the number of hospital inpatient beds has decreased.

In the context of general electricity consumption, in our experience the quota necessary to operate the electromedical devices is equal to $30 \%$.

\subsection{Overall Increase in Available Electrical Power and Healthcare Safety}

The overall increase, from 1,000 to $3,200 \mathrm{kVA}$, of the first two generator sets that serviced the initial installation of the 800-bed hospital, has thus ensured the electric safety of a larger number of healthcare services and activities and other care operations also performed in the Emergency Department, which had not originally been envisaged in this hospital, but were concentrated here following the closure of other hospitals in Trieste.

\section{Conclusions}

The health and technical legislation has established principles for guaranteeing the continuous electricity supply necessary for the safety of the people treated in hospitals. This paper has the aim of reviewing the real dimensioning of power and consumption dedicated to technological installations relative to power supply safety in the hospital, to give greater content to the general principles. 
In conclusion, for us it is important to correlate the power of the electric generator sets and UPS installed with the overall consumption of the hospital services and to have a reserve, to substitute those not in operation during planned maintenance and repair of faults. The presence of an Emergency Department in the hospital and the fact that it is the only hospital in a catchment area of over 235,000 patients, obliges the hospital administration to prepare action plans to cope with any further damaging or catastrophic event.

\section{Acknowledgment}

We thank the other engineers and technicians from the contracted services both for their efficacious activity of maintenance and control of the generator sets and UPS operations.

\section{References}

[1] Decree of the President of the Italian Republic DPR 14 January 1997. “Approval of the Guidelines Addressed to the Regions and Autonomous Provinces Concerning the Minimum Structural, Technological and Organizational Requirements for the Exercise of Healthcare Activities by Public and Private Facilities.” Official Gazette GU 20 February 1997 n. 42 SO, Italy.

[2] Friuli Venezia Giulia, Regional Law LR n. 8, 9 March 2001. "Urgent Measures for the Implementation of Legislative Decree n. 502 of 30 December 1992, as Amended by Legislative Decree n. 229 of 19 June 1999, and Other Measures Concerning Health and Social Policies.” Annex n. 1, Official Regional Bulletin BUR n. 11/2001.
[3] Decree of the Ministry for the Interior DM 18/9/2002. "Approval of the Technical Fire Prevention Rule for Planning, Building and Administration of Public and Private Health Facilities.” GU n. 227 of 27-9-2002, Italy.

[4] Italian Electrotechnical Committee CEI 64-8/2 Electrical installations at nominal voltage not higher than $1000 \mathrm{~V}$ alternating current and $1500 \mathrm{~V}$ direct current. Part 2: Definitions, art. 21.5, Milan 2012-6.

[5] CEI 64-8/3 Electrical installations at nominal voltage not higher than $1000 \mathrm{~V}$ alternating current and $1500 \mathrm{~V}$ direct current. Part 3: General assessment, art. 352, Milan 2012.

[6] CEI 64-8/7 Electrical installations at nominal voltage not higher than $1000 \mathrm{~V}$ alternating current and $1500 \mathrm{~V}$ direct current. Part 7: Requirements for special installations or locations, Ed. 6/2012.

[7] Iatauro, D. 2010. “The Energy Indicators in Hospitals.” ENEA Workshop, Rome.

[8] Rubini, L., Sirtori, L., and Vivoli, F. P. 2004. "Energy Demand in Italian Hospitals.” ISES Italy, Rome.

[9] Nardin, G. 2015. "Energy Supply Cost Structure in Hospitals in the Friuli Venezia Giullia.” University of Udine, Italy.

[10] Stroili Manuela Advisor Thesis Master's in Clinical Engineering, University of Trieste, Italy:

A-German, G. 1998. "Accreditation of a Service of Clinical Engineering in a Hospital: Design of Procedures for the Management of the Electrical Safety of Medical Devices.”

B-Fatuzzo, G. 2007. "Medical Devices. The Evolution of the Concept of Security in Time and Territory." C-Benedetti, G. 2008. "Health Planning in Clinical Risk Management; analysis as the First Phase."

D-Carlassare, N. 2011. "Quality and Safety Planning for Medical Equipment Management.”

E-Bono, M. 2012. "Technology Assessment for the Acquisition of the Intraoperative Radiotherapy (IORT) and Design Criteria.” 